\title{
Os livros nossos amigos, de Eduardo Frieiro: breve história editorial
}

\author{
Maria da Conceiçãa Carvalho ${ }^{1}$ \\ Universidade Federal de Minas Gerais
}

\begin{abstract}
"Guardo de Frieiro a melhor das impressões. A sua vastíssima cultura literária fazia dele uma espécie de enciclopédia viva a que podíamos recorrer sempre".
\end{abstract}

Ângela Vaz Leão

\section{ntrodução}

Publicado em primeira edição em 1941 pela Editora Bluhm, de Belo Horizonte, Os livros nossos amigos de Eduardo Frieiro (1989-1982) parte da referência proustiana sugerida no título - la lecture est une amitié - e faz, ao longo de 139 páginas, uma declaração de amor ao livro ao mesmo tempo objeto material e instrumento do pensamento humano.

O texto original de Os livros nossos amigos, pensado assim, sem vírgula, segundo nos parece não nasce da vontade do Frieiro leitor e crítico, de distinguir os livros - alguns, não todos os livros do mundo - que lhe permitiram praticar a leitura, durante uma vida inteira, como um ato de amor ou amizade. Com esse propósito ele escreveu ensaios e críticas que continuam a merecer o interesse de estudiosos e amantes da literatura. O texto que aqui nos ocupa seria resultado do interesse incondicional pelo objeto livro e pela investigação 
acurada de tudo que a ele se relaciona por parte do bibliógrafo, editor e historiador do livro e da edição (sobretudo de Minas, mas também do Brasil e da América Latina), papéis que o escritor Eduardo Frieiro desempenhou igualmente com destaque durante sua longa vida produtiva. Em trabalhos anteriores (CARVALHO, 2005 e CARVALHO, 2008) abordamos o seu envolvimento com o ofício da edição e sua preocupação com a produção e a circulação da cultura numa Belo Horizonte com poucas décadas de fundação, capital de um estado

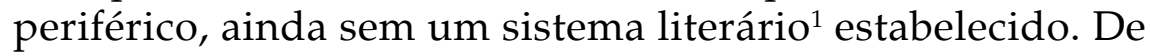
fato, pelo menos no período em que foram publicados seus primeiros livros, inclusive as duas primeiras edições de Os livros nossos amigos, ainda não havia na capital mineira a configuração do ofício do editor baseada na relação complexa com os autores, na escolha criteriosa dos textos a serem publicados, na seleção das formas do livro e na expectativa de uma comunidade de leitores.

Este artigo se propõe a acompanhar as seis edições conhecidas $(1941,1945,1957,1980,1999$ e 2007) procurando detectar as alterações de uma edição à outra motivadas, pelo menos no que se refere às quatro primeiras, pela grande preocupação de Frieiro em aperfeiçoar sem descanso o seu trabalho intelectual, somada à sua intolerância com o livro mal editado. O eixo condutor dessa leitura situa-se dentro das possibilidades da bibliografia histórica e da sociologia de textos discutidas por MACKENZIE (1986), na medida em que esses campos de estudos se preocupam com o rastreio de um texto através das diferentes edições em que foi dado a público com ênfase no seu aspecto material e enquanto testemunho

${ }^{1}$ No sentido pensado por Antonio Candido da existência de uma estrutura nacional/regional sustentada pelo tripé escritores / editores/leitores. 
documental o que, de certa forma, difere da crítica textual com seu método rigoroso de estudo e classificação dos textos e das edições, e, em casos especiais, a averiguação da sua autenticidade e a fundamentada identificação de textos apócrifos e de edições fraudulentas (CARVALHO E SILVA, 1994). Assim, é preciso deixar claro, o que será aqui apresentado é uma breve história editorial deste livro sobre livros que, no conjunto da obra do escritor mineiro, está entre seus ensaios mais conhecidos e reeditados.

\section{Reflexões de um amigo dos livros}

O filho de imigrantes espanhóis sem letras, que desde muito cedo se rende ao vício da leitura, elabora na maturidade ${ }^{2}$ um apaixonado testemunho de sua bibliofilia. Verdadeiro tratado sobre as diferentes dimensões do livro e do ato de ler - histórica, tipográfica, afetiva, estética, comercial-, só não há proselitismo na proposta do livro. Afirma ele ao final do primeiro capítulo:

Há, decerto, uma arte de amar os livros; mas é uma arte sutil que não se ensina. Os amorosos do livro já nascem feitos, sob um signo favorável. Pertencem ao número dos predestinados para os quais o livro se apresenta como coisa imprescindível à vida. São dos que não podem viver sem êle e que o consideram como parte de si mesmos. Por essa razão estão sempre a falar dos livros e do amor que lhes consagram, o que confirma a veracidade de sua paixão. $\mathrm{Na}$ verdade (a frase é de Charles Nodier), "depois do prazer de possuir livros, não há outro mais grato que o de falar dêles". (FRIEIRO, 1941, p.10-11)

${ }^{2}$ Em 1941 já havia publicado sete livros, sendo os três primeiros por sua própria conta, sob o nome de uma editora fictícia e quatro sob o sistema de consórcio editorial, idealizado por ele. 
A primeira edição dessa "conversa sobre livros" saiu em maio de 1941 pela Livraria Editôra Paulo Bluhm de Belo Horizonte. Para Frieiro, como para grande parte dos escritores mineiros das três primeiras décadas do século XX, acostumados a editar seus livros às próprias expensas, com tiragens reduzidíssimas e distribuição precária, ser publicado por uma editora comercial representava uma novidade. Não que nosso autor desconhecesse a dinâmica da edição moderna definida por critérios intelectuais, técnicos e comerciais. Ao contrário, tinha grande interesse pelo tema sobre o qual lia e pesquisava, além da experiência de mais de trinta anos na Imprensa Oficial de Minas, onde começou a trabalhar ainda criança como aprendiz de tipógrafo e aposentou-se como redator. Lá atuou sempre com o esmero e o cuidado de quem acredita, como Mckenzie (1986), que forma e conteúdo interagem na apreensão dos sentidos através da palavra escrita. Amava os livros como "perfeitas máquinas de ler"3 e desfrutava do prazer estético de ser o escritor e o impressor de suas próprias obras. Mas tinha, também, a preocupação do editor, no sentido bourdieusiano, de atuar como agente social com poder para consagrar objetos e distinguir pessoas. Neste sentido ele já tinha passado, naquele momento, pela experiência de idealizar e coordenar o consórcio editorial "Os Amigos do Livro" $^{4}$ em que experimentou com êxito a função de atribuir

\footnotetext{
${ }^{3}$ Em Os livros nossos amigos (1941) , p. 13, escreve: "Se Le Corbusier chamou à boa casa máquina de morar, Paul Valéry disse que o belo livro é uma perfeita máquina de ler".

${ }^{4}$ Cf. CARVALHO. Sociedade Editorial Os Amigos do Livro: um caso de mediação cultural. In: VAZ, A. E. A. et al. Literatura em revista (e em jornal): periódicos do Rio Grande do Sul e de Minas Gerais. Belo Horizonte: FALE/UFMG; Rio Grande: PPG/Letras/ Fund. Univ. Federal do Rio Grande, 2005. p. 107-136.
} 
valor a textos inéditos e a jovens escritores tirando os lucros simbólicos dessa operação.

Contudo, mesmo tendo propiciado a edição de importantes obras dos jovens modernistas mineiros, aquele empreendimento não alterou a estrutura do cenário editorial de Minas Gerais. Em outras palavras, vivendo e produzindo na periferia de um Brasil que apenas iniciava seu processo de industrialização, o escritor mineiro que quisesse ver seu texto publicado via-se obrigado a procurar editor no Rio, São Paulo, ou Porto Alegre, ou a imprimir seu livro às próprias custas, servindo-se dos serviços tipográficos da Imprensa Oficial ou de pequenas e mal aparelhadas tipografias. Em 1937 Frieiro escreve:

O livro destinado à venda é um produto mercantil como qualquer outro; precisa de editores e distribuidores, publicidade e organização comercial, bom mercado interno e externo. Estado rural e pastoril, de população rarefeita e em grande parte analfabeta, sem grandes cidades e sem grande imprensa, Minas Gerais não oferece boas condições para a produção do livro, é ainda um fraco mercado livreiro. Essa a razão por que não temos editores. Por enquanto só produzimos ... consumo. (FRIEIRO, 1937, p.7)

Assim, em 1939, quando o livreiro Paulo Bluhm, dono de uma livraria na Rua da Bahia, resolve ampliar os negócios abrindo uma filial e iniciando também as atividades de edição, é Frieiro que lhe prestará algum tipo de assessoria na criação da Livraria Editôra Paulo Bluhm. Sintomaticamente o nome da primeira coleção será Os Nossos, cuja proposta era dar à luz manuscritos de intelectuais mineiros, que aguardavam na gaveta a abertura do campo editorial local.

Os livros nossos amigos será o terceiro dessa coleção a ser dado a público. Pequena brochura de 19 por $12,5 \mathrm{~cm}$, impresso na Imprensa Oficial, é apresentada em elegante diagramação 
sugerindo a presença do Frieiro artista gráfico e seu prazer declarado de dirigir e acompanhar a feitura de um livro. No segundo capítulo intitulado "A tectônica da 'máquina de ler'" essa exigência se revela:

Não basta o gosto dos livros. Agrada-nos saber também como são feitos. Todo amor aspira a compreender o objeto amado, para que este se lhe revele em seu valor total. $\mathrm{O}$ perfeito bibliófilo deve possuir noções da arte de bem imprimir. Precisa saber como se faz o livro, de modo a ser capaz de apreciar-lhe toda a beleza e julgar das sábias regras que presidem a sua execução. (FRIEIRO, 1941, p.12)

Da capa elegante, sem informações supérfluas, tipos azuis sobre fundo branco, às margens generosas do miolo, pode-se imaginar que a forma material dessa primeira edição terá agradado ao autor em consonância com o sentimento que ele exprime também no capítulo dois:

Os que amam os livros e teem a paixão da bibliografia, os que se enlevam na contemplação duma página impressa com pulcritude, com elegância, sem a mais pequena falta de impressão, esses concordarão conosco: a arte de imprimir é a mais amável das artes. ${ }^{5}$ (FRIEIRO, 1941, p.13)

E quanto aos críticos? O que se sabe da recepção de Os livros nossos amigos pela crítica? A biobibliografia de Frieiro elaborada por A. S. Vieira (VIEIRA,1967) demonstra a atenção que esse pequeno livro mereceu do jornalismo literário ao longo do ano de 1941. Dos principais jornais de São Paulo, Rio de Janeiro, Salvador e Belo Horizonte críticos literários como Brito Broca, Eloi Pontes, Ivan Lins, Afrânio Coutinho, Guilhermino César,

${ }^{5}$ Optamos por manter a ortografia conforme aparece em cada edição citada. 
Oscar Mendes, João Dornas Filho, João Camilo de Oliveira Torres, entre outros, receberam a obra com interesse.

Do mesmo modo, na correspondência ativa e passiva de Frieiro, do período, pode-se acompanhar não apenas as críticas mais pontuais que foram feitas ao livro como também a forma como o autor as recebeu. A título de exemplo tomo uma carta de Frieiro ao filósofo Ivan Lins (1904-1975), datada de 5 de outubro de 1941.

Li com grande satisfação o excelente artigo que escreveu no Correio da Manhã a respeito de Os livros nossos amigos. Felicito-me por haver o meu livrinho suscitado e merecido tão interessante comentário. E quero exprimir-lhe aqui os meus agradecimentos pela maneira desvanecedora com que se referiu ao meu nome.

Não creio que o livrinho venha a ter nova edição, como lhe vaticina o generoso confrade. Mas, se vier a tê-la - hipótese bastante improvável-, emendarei todos os deslizes ou equívocos que nele me escaparam [...]

De fato, não obstante os termos elogiosos que empresta a Os livros nossos amigos, Ivan Lins aponta dois aspectos com os quais não concorda e que provocam a reação de Frieiro. Não seria esta a primeira nem a última vez em que o nosso escritor se mostraria irritado pela "equivocada" apropriação de sua obra, temeroso de que os significados por ele atribuídos dificilmente sobreviveriam à recepção pelo público. Continua a carta:

[...] sem embargo do grande apreço em que tenho o seu juízo crítico, não estou muito convencido da validade dos reparos que faz. Creio, até, que posso sustentar com boas razões o que deixei escrito nas passagens que provocaram a sua crítica. 
A primeira objeção de Lins refere-se ao uso da expressão Ad usum Delphini inserida no capítulo XII, página 86. Discordando da crítica Frieiro retira de sua estante o Grande Larousse, de 1865 e transcreve na carta, integralmente, o verbete em questão. E conclui, com alguma ironia:

Ora, neste ponto, eu acato a informação do Larousse, salvo se o do século XX (que não tenho agora ao alcance da mão) diz cousa que contradiga o do século XIX. Se houve retificação na grave enciclopédia, eu também retificarei o que escrevi. Se não, não vejo motivo.

Dono de grande erudição e sólida cultura humanística o filósofo Ivan Lins ficou conhecido por sua adesão ao positivismo de Augusto Comte. São, de fato, aspectos relacionados a essa figura, os outros pontos que questiona no livro de Frieiro. Entretanto, o que nos interessa aqui é a resposta do escritor mineiro, angustiado diante da chamada instabilidade textual, a tentação que tem certos escritores de alterar continuadamente os seus textos. Continua a carta:

Quanto ao segundo ponto em que sou chamado a emendar a mão, o que se refere ao plano da biblioteca mínima elaborada por Comte, penitencio-me, aqui muito em particular, de haver cedido a certa inclinação frívola que sempre houve em mim, para a ironia e a irreverência [...] Cabe-lhe censurar-me, concordo, por me haver referido, burla burlando, à "paciência bovina" do grande filósofo de sua maior devoção.

E ainda, sobre a mudança solicitada por Lins para trocar a expressão "Templo da Humanidade" por "Capela da

${ }^{6}$ Edições de clássicos franceses em que certas passagens teriam sido expurgadas a mando de Luís XIV para a leitura de seu filho, o Delfim da França. 
Humanidade" ao se referir ao Centro, em Paris, dos seguidores de Augusto Comte:

Para mim, já não há dúvida possível [após consultar suas fontes de informação], a menos que não se queira dar à palavra "capela" o sentido de "templo", que também se lhe dá. Não me custará, entretanto, emendar numa segunda edição (se a houver) "templo da Humanidade" por "Capela da Humanidade".

\section{Reescrever sempre}

A incerteza em relação a uma segunda edição, na verdade uma falsa modéstia que fazia parte, em certa medida, do código de boas maneiras nas relações literárias da época, revela, por outro lado, aquela obsessão já mencionada com que Frieiro reescrevia e modificava seus textos, perseguindo a consecução da "perfeita máquina de ler".

Em carta a Hernâni de Campos Seabra, em 3 de junho de 1943, revela: "A terceira (sic) edição, ${ }^{7}$ melhorada, de Os livros nossos amigos tenho-a preparada há muito. Falta só o editor." Sem outras informações sobre esta espera, o que se sabe é que o editor da primeira edição com quem Frieiro tinha uma relação de confiança, havia se transferido para o Rio de Janeiro, após ter tido sua livraria depredada por populares da cidade, na onda de intolerância contra imigrantes alemães e italianos, associados indistintamente ao nazismo. Assim, somente em

\footnotetext{
${ }^{7}$ Parece ter havido aqui um ato falho do escritor ao escrever "terceira edição" quando, na verdade, trata-se da segunda. Como esta edição aumentada já estava pronta há muito, no fundo da gaveta, ele já trazia, de fato, o pensamento voltado para as mudanças que preparava para a terceira edição.
} 
1945 sairá pela Livraria Inconfidência S / A, de Belo Horizonte, a segunda edição, provavelmente com o assessoramento tipográfico do escritor.

A variação entre a primeira e a segunda edição é substancial. Uma nota no verso da página de rosto informa que a presente edição aparece acrescida de nove capítulos, a saber: "Tristeza e alegria do bibliófilo pobre", "O Diabo nas tipografias", "Ainda o Diabo nas tipografias", "O escritor e as provas", "Corrigir provas", "Lapsos, disparates e bernardices", "Escritores impressores", "A letra é sagrada" e "Tôda palavra impressa é um monumento a Gutenberg". Parece haver, nesta edição aumentada, um aprofundamento na tentativa de abarcar, tanto quanto possivel, as situações que perpassam a relação entre um bibliófilo e seu objeto de desejo. E não será difícil perceber, em títulos e subtítulos ou nos casos explorados em cada um dos assuntos, o reflexo da vida do escritor em questão que, segundo ele mesmo, "contraíra cedo o gôsto pelos livros e adquirira uma personalidade 'impressa' [...]" (FRIEIRO, 1945, p.155).

Porém, as alterações vão além dos novos capítulos. Embora não caiba no espaço deste artigo uma análise textual detalhada, o cotejo que fizemos entre a primeira e a segunda edição mostra que cada capítulo sofreu cortes e acréscimos que vão de um termo ou uma frase a páginas inteiras modificadas. Por exemplo: alguns estrangeirismos usados na primeira edição são traduzidos na segunda: "na opinião dos reviewers" ( $1^{a}$ ed., p.27) passa a ser "na opinião dos críticos" ( $2^{a}$ ed. p.25); a "mamá" da primeira edição será "mamãe" na segunda. Há mudanças ortográficas (teem por têm; indu por hindu), estilísticas (bibliotáfios por bibliótafos - ambas as formas são aceitáveis; "algumas composições desta índole" muda para "algumas composições deste jeito") e cochilos de impressão que passaram na primeira edição - Leaves of [B] rass corrigido para Leaves of Grass, - que são acertados na segunda. Mas, o mais 
interessante a destacar é que, como anti-dogmático confesso, Frieiro vê com naturalidade as mudanças ideológicas e estéticas pelas quais um indivíduo - ele está falando aqui do leitor e do bibliófilo - passa ao longo de sua existência. Assim, o capítulo intitulado "Plano duma biblioteca mínima" começa por receber, na segunda edição, um adendo entre parênteses (para um leitor mediano). Identificado o seu leitor modelo, ele procura justificar a ausência de tantos livros canônicos, que não entraram nesta lista de 20 itens. Além disso, esta lista é diferente daquela da primeira edição, não apenas pela substituição de autores e/ou títulos, como também porque ele amplia a discussão sobre o Cânone e justifica as mudanças em decorrência das suas predileções atuais. Na segunda edição o autor procura não apenas discutir questões contingenciais - $\mathrm{o}$ comércio de livros de segunda mão num difícil período de guerra mundial - como traz novas informações sobre certas questões que ele continuava pesquisando. Assim, se ao abordar as fontes bibliográficas a primeira edição só incluía manuais e repertórios portugueses e brasileiros, a segunda já traz fontes gerais francesas, italianas e espanholas. Do mesmo modo, as questões específicas do nosso país ganham destaque: o capítulo sobre Ex-libris tem dois parágrafos adicionais sobre colecionadores brasileiros e, ao abordar os inimigos dos livros, no capítulo $\mathrm{XV}$, acrescenta um parágrafo sobre a ação deteriorante da luz e da poeira sobre os livros, problemas característicos das regiões tropicais.

Como curiosidade, mas também para desmentir a fama de turrão e espírito amargo que acompanhou Frieiro em vida, fomos conferir a promessa que ele fizera a Ivan Lins de rever alguns pontos, se houvesse nova edição. Pois, a "paciência bovina" de Augusto Comte foi substituída por "paciência exemplaríssima" (p.53) e o "Templo da Humanidade" se transmutou em "Capela da Humanidade". Este é, além do 
mais, um pequeno fato para ilustrar as redes de sociabilidade que interligam as comunidades literárias e afetam até mesmo, se quisermos exagerar, a noção de autoria.

No que tange à arquitetura do livro ou à mise en page também há mudanças que modernizam e embelezam o volume. Um pouco menor que a edição anterior é uma brochura de $17 \mathrm{~cm}$ por $11 \mathrm{~cm}$, com duas inovações na nomenclatura e na organização/ distribuição das informações bibliográficas, a saber: na primeira edição o que hoje chamamos sumário é identificado como índice e aparece no final do livro, o que era comum nas edições da época. Na segunda edição o nome da seção passa a ser Tábua das Matérias o que, salvo engano, é tirado da tradição editorial francesa, e é mantida no final do livro. Oelemento tipográfico que vem dar mais visibilidade ao conteúdo de cada capítulo é uma espécie de resumo escrito em tipos reduzidos, referente aos temas abordados ali, e que vem logo abaixo do título do capítulo. Este recurso introduzido na segunda edição será repetido em todas as quatro seguintes, embora publicadas por casas editoras diferentes.

A recepção da segunda edição pela crítica brasileira foi igualmente ampla em número de artigos críticos publicados nos principais jornais ${ }^{8}$ do país, e calorosa, conforme se apreende da correspondência de Frieiro. Pinço no arquivo de cartas enviadas por ele, uma de 12 de setembro de 1945, ao historiador Hélio Vianna. Assim começa a missiva:

Prezado Prof. Hélio Vianna:

Recebi sua carta com o recorte do artigo de Roberto Seidl. Eu já o conhecia, mas agradeço-lhe a sua grande gentileza lembrando-se de me enviar. Esqueci-me, a vez passada, de me referir à nota do "Jornal do Comércio" sôbre a segunda edição de "Os livros nossos amigos". Também era minha

${ }^{8}$ Cf. VIEIRA. Eduardo Frieiro; bibliografia. Belo Horizonte: Escola de Biblioteconomia, 1967. [Inédito] 
conhecida, por sinal que reproduzia quase inteiramente a que saíra no velho órgão por ocasião da primeira edição. E já dessa vez o autor da nota - aliás cheia de boa vontade para com o livrinho inticava (sic) com a falta duma vírgula no título. Êle sabe português e teve certa razão em estranhar a ausência da vírgula. Eu também sei algum, e achei que podia dispensar a vírgula. Opiniões sustentáveis, ambas.

Muita gente estranhou a falta da vírgula que, na intenção do autor, relativisa os sujeitos da frase. Nem todo livro merece a nossa leitura! Frieiro não abria mão dessa assertiva e segue perseguindo a ideia improvável de uma "edição definitiva" do seu livro sobre os livros.

\section{Em busca de editor}

Duas cartas escritas em 1947 revelam alguma coisa da inquietação do nosso escritor com essa impossível completude de uma obra. Em 4 de agosto de 1947 respondendo a um bibliófilo do Rio de Janeiro que lhe escrevera pedindo sugestões de livros sobre bibliologia informa a certa altura:

A segunda edição de "Os livros nossos amigos" (Livraria Inconfidência S/A, Belo Horizonte, 1945) saiu melhorada e com nove capítulos que não figuravam na primeira. Tenho já prontos os originais para uma possível terceira edição, melhor e maior que a segunda.

E ao escritor paulista Hernani de Campos Seabra, escreve em 18 de outubro de 1947:

Livro lindo, o que me mandou, e sem dúvida do maior interêsse para mim. Entre os capítulos que faltam a $O s$ livros nossos amigos, e nele não foram incluídos unicamente por não aumentar o volume além de certo limite de páginas, um é precisamente o dos "livros de arte" ou "livros 
de luxo". Este ficará para a terceira edição, que já preparei, muito melhorada, e que só aguarda editor. (Grifo do autor)

A recorrência desta última afirmação nas cartas de Frieiro merece um comentário sobre a sua relação curiosa com os editores. Autonomeado "homem impresso" por estar ligado profissional e afetivamente a todas as nuances da cadeia do livro e da leitura, Frieiro tinha, entretanto, uma certa dificuldade em negociar com os editores profissionais. A sua correspondência desvela um número significativo de convites que lhe chegavam de editoras do Rio, São Paulo, Porto Alegre, Buenos Aires, para que ele publicasse algum livro ou artigo, ou traduzisse livros do espanhol, convites que ele sistematicamente respondia com evasivas, embora tivesse sempre textos prontos ou em preparo ... a espera de editor. ${ }^{9}$ As reflexões de Bourdieu $(1977,1982)$ podem nos ajudar a compreender as dificuldades de Frieiro para se situar no campo de produção dos bens simbólicos. De fato, como agente ocupando uma posição no campo da produção literária, ele, como qualquer trabalhador intelectual, concorre com os outros agentes (editores, críticos, ilustradores) em torno da questão do valor dos seus produtos. Na relação escritor/editor, específicamente, o primeiro depende da estrutura de produção do editor para transformar a sua arte-o manuscrito-em objeto de valor de troca - o livro. O editor, de sua parte, depende do escritor para lhe fornecer a matéria prima para a sua empresa de transformação. A posição do autor na hierarquia dos graus de consagração (autor desconhecido, autor consagrado, autor da Casa, etc.) articula-se com a posição do editor no sistema de produção e circulação (editor comercial, editor cultural, editor consagrado, etc). Sabemos que os tipos de acordos conseguidos nessa relação é que definem o funcionamento do campo e a estrutura das obras produzidas.

${ }^{9}$ Cf. CARVALHO. Cordialmente, Eduardo Frieiro: fragmentos (auto)biográficos. Belo Horizonte: POSLIT/FALE/UFMG, 2008. (Tese) 
O que há de singular na história de Frieiro é que, mesmo já dispondo de um capital cultural suficiente para ser disputado por editoras bem estabelecidas no mercado e que atuam na mesma linha editorial que lhe interessa pertencer, ele hesita em entrar no que Bourdieu chama de luta concorrencial. Um trecho de carta escrita ao professor espanhol Sánchez-Sáez, em 10 de novembro de 1945, ilustra bem o que parece ser uma desconfiança sua exagerada em relação à autoridade dessa instância de consagração, o editor:

[...] Se eu tivesse facilidade de encontrar editor para a matéria gostaria de publicar um volume com os artigos que já escrevi e mais alguns que tenciono escrever sobre letras hispanas. Mas não creio que o encontre - e tanto mais que não o procuro ...[...]

Mas, felizmente para ele próprio e para os seus leitores, ele encontra formas de contornar o seu temperamento desconfiado e continua publicando em Minas e fora de Minas, como veremos a seguir.

A terceira edição de Os livros nossos amigos, que Frieiro considerava a mais completa e definitiva, ${ }^{10}$ foi fruto de um convite especial a ele feito pela Editora "O Pensamento", de São Paulo que, parece, venceu as suas resistências habituais. $\mathrm{O}$ Prefácio desta edição, escrito pelos editores (Diaulas Riedel era um deles) vale a pena ser lido na íntegra para que se compreenda melhor a aquiescência de Frieiro.

A Emprêsa Editora "O Pensamento", que neste ano [1957] comemora cinqüenta anos de atividades editoriais, não quis que tão grata efeméride decorresse sem algo que a marcasse de forma duradoura. Em lugar das ruidosas e habituais

${ }^{10}$ A $5^{a}$ (1999) e a $6^{\text {a }}$ (2007) edições sairam quando ele já havia falecido. 
festividades, pensamos que a maneira mais nobre de nos congratularmos por êste meio centenário de trabalho, seria a de uma edição especial que, embora fugindo ao espírito que tem caracterizado nossa linha editorial, representasse uma homenagem da nossa Emprêsa não apenas a todos quantos nela têm cooperado, mas principalmente ‘aquele que tem sido a razão de ser de todos os nossos esforços e dedicação - o livro. Milhares de volumes existem que, de uma forma ou de outra, exaltaram o papel benéfico e a alta função civilizadora dêsse grande benfeitor da humanidade. Nenhum, porém, que reunisse tantas qualidades como a pequena obra prima "Os livros nossos amigos", de Eduardo Frieiro e que, editado na Província, não alcançou talvez a repercussão de que é merecedora. De tudo encontramos nas páginas deste volume, indispensável na estante de quem quer que possua algum amor ao papel impresso. Idéias, sugestões, definições, curiosidades, inteligência, bom gosto, informações, estilo, de tudo encontramos em "Os livros nossos amigos". Nenhuma outra obra poderia dizer mais e melhor sobre o livro.

É, pois, com justo orgulho que marcamos nosso cinquentenário com esta edição. Estamos certos de que não poderíamos prestar mais bela homenagem ao livro do que pondo de novo em circulação as páginas com que Eduardo Frieiro - a quem agradecemos a aquiescência desta edição - soube fazer-lhe o elogio e compreende-lo em tôda sua nobre e alta função civilizatória.

Elegante apresentação gráfica, esta edição segue a mesma organização e distribuição das matérias da anterior mas com variações de conteúdo informadas no verso da folha de rosto:

\footnotetext{
"A presente edição, revista e aumentada, contém cinco capítulos novos: "O verdadeiro bibliófilo"; "Contra os livros"; "Santo Eça, mártir das tipografias"; "A indumentária do livro" e "Títulos de livros".
} 
O Capítulo Plano duma biblioteca mínima (para um leitor mediano),que figurava nas edições anteriores, foi suprimido nesta.

Além do mais, das três edições, esta é a que chega mais perto daquilo que embalava os sonhos de Frieiro: "o livro pulcramente editado" sem os detestáveis (mas quase inevitáveis) erros tipográficos. Em carta ao professor de filosofia Walter Silveira da Mota, de São Paulo, datada de 31 de março de 1968, Frieiro expressa a sua opinião sobre as três edições do livro em questão:

Estou-lhe enviando por êste correio, com todo o prazer, um exemplar de "Os livros nossos amigos", segunda edição, 1945. É incomparavelmente superior à que conheceu, de 1941, reduzida. Mas a melhor é a terceira, refundida, com cinco capítulos novos, publicada pela Editôra "O Pensamento", de São Paulo, 1957. Há muito não se acha em Belo Horizonte. Penso que não será difícil encontrá-la em São Paulo ...

Mas, nem mesmo esta edição satisfazia ao autor, embora a recepção dos críticos tenha sido, mais uma vez, muito positiva. Respondendo ao machadiano R. Magalhães Júnior ele diz:

Não li seu artigo sobre "Os livros nossos amigos" na Fôlha da Noite de São Paulo. Lamento-o, mas ainda espero lê-lo. De qualquer modo agradeço-lhe a bondade de se ter ocupado com aquela obra, o que para mim representa um motivo de grande e especial desvanecimento, como não é para menos.

Porém, um comentário na carta do amigo deixa o nosso escritor quase inconsolável:

Não há desculpas, vejo-o agora, para o meu esquecimento do capítulo de Machado sobre o bibliômano. Como não me lembrei dele? Memória ruim, nada mais. Ficará para a próxima vez, porque espero dar outra edição com novos recheios. 
A quarta edição só saiu em 1980, em comemoração aos 90 anos de Eduardo Frieiro, quando ele já quase não enxergava mais e estava distanciado das atividades que tanto deram sentido à sua vida: ler, escrever e editar. Foi publicada pela Coordenadoria de Cultura de Minas Gerias, dentro de um programa editorial que visava reeditar autores e livros expressivos da cultura mineira. Do ponto de vista de conteúdo não há, pois, nenhuma variação em relação à terceira edição, tida daí em diante como o texto estabelecido pelo autor; também não se destaca pelas artes gráficas, editado como brochura com miolo colado. O que há de significativo nesta edição é um longo prefácio, na verdade chamado de "Alguns Apontamentos" por quem o assina, o jornalista e escritor Moacyr Andrade. São nove páginas e meia de uma conversa saborosa retratando o amigo escritor e ex-companheiro de trabalho na Imprensa Oficial.

\section{Outras edições}

Uma quinta edição saiu em 1999 pela Editora Itatiaia, de Belo Horizonte, que havia negociado, muitos anos antes, diretamente com Eduardo Frieiro, os direitos de publicação de sua obra completa. É uma edição caracterizada por intervenções não autorais e, não obstante a tentativa dos editores de renovação do ponto de vista de produção editorial - brochura com orelhas contendo informações sobre o autor, capa de um artista plástico reconhecido, e ficha catalográfica - está marcada pelo excessivo número de erros tipográficos, o que teria desgostado profundamente a Frieiro, se vivo fosse. Aliás, cartas a amigos escritores já revelavam sua irritação para com os editores daquela Casa que, com o propósito de minimizar os custos de produção, vinham comprometendo a qualidade material dos livros publicados com a sua marca. Nesta quinta edição de Os livros nossos amigos mantém-se o prefácio de 
Moacyr de Andrade presente na edição anterior, mas suprimese, sem razão aparente, a epígrafe escolhida por Frieiro desde a primeira edição, a frase de Proust La lecture est une amitié, e que, como convém a uma epígrafe no universo textual, desvela, sem escancarar, as intenções do autor sobre o modo como deseja ser lido. Nesse caso específico de modificação não autoral pensamos como Carvalho e Silva (1994) tratar-se de mais um caso de edições com erros e grosseiras deturpações, infelizmente ainda comuns no mercado de livros no Brasil.

A sexta, e até o presente momento última edição de Os livros nossos amigos foi publicada em 2007, em comemoração aos 10 anos de criação do Conselho Editorial do Senado Federal, aparecendo como volume 80 da coleção intitulada Edições do Senado Federal. A proposta de tal edição, conforme consta no verso da folha-de-rosto é buscar "editar, sempre, obras de valor histórico e cultural e de importância relevante para a compreensão da história política, econômica e social do Brasil e reflexão sobre os destinos do país." Na quarta capa o livro de Frieiro é celebrado como "um hino de amor incondicional ao livro" e, ainda, como "uma apaixonada declaração de amor ao livro como objeto e como instrumento do pensamento humano." O pequeno texto se fecha com uma indicação: "Para quem é apaixonado pelo objeto livro e pelo que ele acolhe não pode deixar de se deliciar com esta preciosidade de livro. Este também é um livro para os amantes do livro".

Sendo uma edição para marcar a trajetória de um núcleo editorial do Governo Federal, o resultado é, pode-se dizer, uma produção bem cuidada do ponto de vista material: capa elegante em papel cartão plastificado e miolo impresso em papel vergê areia, letras capitulares iniciando cada capítulo e nenhuma incorreção tipográfica. No que se refere à arquitetura do livro, ou à sua tectônica particular, segundo expressão do próprio Frieiro, a sexta edição se distingue das anteriores em 
alguns aspectos: emprega o termo Sumário para identificar as matérias do livro, trazendo-o para a página após a folha de rosto, como instrui a ABNT; promove o retorno da epígrafe suprimida na edição anterior e, o que teria, certamente, agradado ao autor, insere um índice onomástico de sete páginas e meia.

Dois aspectos, entretanto, relativizam a qualidade dessa edição: o primeiro trata-se da vírgula inserida no título - os livros, nossos amigos - que altera o sentido desejado pelo autor, o qual teve oportunidade de declarar em conversa epistolar com seus interlocutores, conforme já mostramos; como segundo chama nossa atenção o tamanho reduzido, na capa e na lombada, da fonte usada para o nome do autor, obscurecido por outra informação que parece ser, na intenção do editor, a verdadeira autoria, a saber, Edições do Senado Federal. Ou seja, à maneira das primeiras produções da imprensa renascentista, nessa sexta edição de Os livros nossos amigos, o crédito de autoria da obra impressa quase se equipara entre o tipógrafo/editor que a construiu materialmente e aquele que concebeu o texto.

\section{À guisa de conclusão}

Do ponto de vista da sociologia de textos, seria problemático falar sobre "uma obra" como algo distinto e independente, da história de suas versões ou edições, podendose considerá-la, ao contrário, como algo instável, cuja expressão material estaria sempre permeável a novas intervenções autorais e não autorais. Entre o labor filológico para reproduzir o texto em sua forma original e os acidentes de percurso que a história da edição de um determinado texto desvenda, haveria uma relação de forças entre a necessidade de zelar pela integridade e fidedignidade do texto como expressão da cultura pessoal ou social e, como lembra McKenzie, a evidência de que cada versão 
reclama seu direito de ser editada à sua própria maneira, respeitando sua historicidade como uma realidade concreta. Mais do que nunca, o resgate do patrimônio cultural escrito é uma tarefa transdisciplinar que conclama os campos disciplinares da Linguística, Letras, História e Biblioteconomia.

\section{Referências Bibliográficas}

BOURDIEU, P. La production de la croyance: contribution à une économie des bien symboliques. Actes de la recherche en Sciences Sociales, 962-63, p. 69-72, 1986.

BOURDIEU, P. As Regras da Arte: gênese e estrutura do campo literário. São Paulo: Cia das Letras, 1996.

CARVALHO, M. C. A Sociedade Os Amigos do Livro: um caso de mediação cultural. In: VAZ, A. E. A. et al. Pesquisa em jornais... Belo Horizonte: FALE/UFMG; Rio Grande: PPG em Letras/FUFRG, 2005.

CARVALHO, M.C. Cordialmente, Eduardo Frieiro: fragmentos (auto)biográficos. Belo Horizonte: FALE/UFMG, 2008. (Tese)

CARVALHO E SILVA, Maximiano de. Crítica textual: conceito, objeto, finalidade. Revista Confluência, Rio de Janeiro: Liceu Literário Português, n.7, p. 57-63, jan./jun., 1994.

CHARTIER, Roger. Cultura escrita, literatura e história: conversas de Roger Chartier com Carlos Aguirre Anaya, Jesús Anaya Rosique, Daniel Goldin e Antonio Saborit. Porto Alegre: Artmed Editora, 2001. p. 45-6.

FRIEIRO, Eduardo. Letras mineiras - 1929-1936. Belo Horizonte: Os amigos do livro, 1937.

FRIEIRO, Eduardo. Os livros nossos amigos. Belo Horizonte: Paulo Bluhm, $1941.139 \mathrm{p}$.

FRIEIRO, E. Os livros nossos amigos. 2. ed. rev. aum. Belo Horizonte: Livraria Inconfidência S.A., 1945. 221 p. 
FRIEIRO, E. Os livros nossos amigos. 3. ed. rev. aum. São Paulo: O Pensamento, 1957. 212 p.

FRIEIRO, E. Os livros nossos amigos. 4. ed. Belo Horizonte: Coord. Cultura MG, 1980. 224 p.

FRIEIRO, E. Os livros nossos amigos. 5. ed. Belo Horizonte: Itatiaia, 1999. $196 \mathrm{p}$.

FRIEIRO, E. Os livros, nossos amigos. 6. ed. Brasilia: Senado Federal, 2007. 198 p.

LEÃO, Ângela Vaz. Conversando sobre Eduardo Frieiro; entrevista concedida a Maria da Conceição Carvalho. Revista do Centro de Estudos Portugueses, UFMG, Belo Horizonte, v.28, n.39, p. 245-253, 2008.

MACKENZIE, D. Bibliography and the sociology of texts: The Panizzi Lectures, 1985. London: The British Library, 1986.

VIEIRA, Anna da Soledade. Eduardo Frieiro: bibliografia. Belo Horizonte: Escola de Biblioteconomia/UFMG, 1967. (Datilografado)

\section{Resumo}

Leitura crítica das seis edições (1941, 1945, 1957, 1980, 1999 e 2007) de Os livros nossos amigos escrito pelo ensaísta, bibliógrafo e editor mineiro Eduardo Frieiro (1989-1982) procurando acompanhar as alterações de uma edição à outra, buscando entender a historicidade de cada uma delas.

\section{Résumé}

Lecture critique des six éditions (1941, 1945, 1957, 1980, 1999 et 2007) de l'oeuvre Os livros nossos amigos, écrit par l'essayiste, bibliographe et éditeur mineiro Eduardo Frieiro (1989-1982) en recherchant les altérations d'une édition à l'autre dans le but de comprendre l'historicité de chacune. 